\title{
Experimental Investigation of Particulate Matter Emissions from a Single Cylinder Diesel Engine Fuelled With Waste Cooking Oil Biodiesel
}

\author{
Liming Xianga, Ziyang Zhang ${ }^{b}$ \\ School of Mechanical and Automobile Engineering, Hubei University of Arts and Science, Xiangyang \\ 441053, China \\ a846410358@qq.com, b405541432@qq.com
}

Keywords: Waste cooking oil, biodiesel, solid particle, lung-deposited surface area.

\begin{abstract}
Advanced biodiesel derived from waste cooking oil (WCO) is a promising diesel alternative because of its renewability and its less negative impact on food supply as compared to traditional biodiesels. WCO biodiesel can be catalytically produced from waste cooking oil and alcohol through the process of trans esterification and esterification. It has already been proven that WCO biodiesel can be used in conventional compression-ignition engines with some minor modifications. Even though it is expected that WCO biodiesel will reduce particulate matter (PM) emissions due to its oxygen content, more studies are needed to quantitatively demonstrate its low PM emissions, especially regarding its lung-deposited surface area (LDSA) concentration. In this study, the engine-out solid particle emissions from WCO biodiesel were investigated in an agricultural single-cylinder diesel engine operated at engine speeds of 1200,1400, 1600 and $1800 \mathrm{rpm}$, and at engine loads of 10 to 95 $\mathrm{Nm}$. Solid particle related parameters, including particle number concentration, mass concentration, mean diameter, and LDSA concentration, were quantitatively analysed by a portable emission measurement system (NanoMet3). Conventional fossil-based diesel was also tested, the results of which were used as a benchmark.
\end{abstract}

\section{Introduction}

Due to decreasing fossil fuel reserves and the need to reduce greenhouse gas emissions and air pollution, biofuels have become an important fossil fuel alternative [1-4]. Advanced biodiesel derived from waste cooking oil (WCO) has an additional advantage over biodiesels derived from vegetable oils, since it has no negative impact on food supply. WCO biodiesel can be catalytically produced by the trans esterification and esterification of long chain fatty acids derived from WCO with alcohols such as methanol or ethanol.

WCO biodiesel can be used in compression-ignition engines with some minor hardware modifications. One of the most attractive features of using biodiesel in compression ignition engines is its low particulate emissions due to its oxygen content [5-6]. Hwang et al. [7] analysed the composition of soot particles emitted from a compression-ignition engine fuelled with WCO biodiesel. They found that, unlike the diesel soot, which was mainly made up of carbon and hydrogen, soot from WCO biodiesel contains lots of oxygen species. Lu et al. [8] experimentally investigated the effect of biodiesel produced from WCO on the particulate emissions of a direct-injection diesel engine. Their results showed that the biodiesel could effectively lower the particle mass and number concentrations in comparison with diesel fuels with ultralow sulphur content. Wei et al. [9] investigated the physical properties and the oxidation reactivity of the particles emitted by a direct injection diesel engine fuelled with WCO biodiesel. They found that the use of biodiesel enhanced particulate oxidation reactivity and the regeneration of soot particles in an after-treatment device. Zhu et al. [10] investigated the particulate emissions of a diesel engine fuelled with the mixtures of WCO biodiesel and pentanol under different engine load conditions. They suggested that WCO biodiesel and pentanol blends can be regarded as an acceptable alternative fuel for diesel engines due to their improved combustion performance and reduced particulate emissions. Betha et al. [11] studied particulate emissions from a domestic stationary diesel generator running on ultralow sulphur diesel and WCO biodiesel under 
different load conditions. Their results showed a decrease in particulate mass and number emissions when the fuel was switched from diesel to WCO biodiesel. However, more ultrafine particles were found in the emissions of WCO biodiesel compared to that of the ultralow sulphur diesel.

Ultrafine particles may lead to harmful health effects. In addition to the number concentration of the ultrafine particles, LDSA may be a suitable measure of dose for predicting pulmonary inflammation resulting from ultrafine particles. Many studies have measured LDSA concentrations in a variety of occupational and non-occupational environments, and different urban areas. Furthermore, LDSA concentrations for various aerosols, for example, coal, biomass, cigarette, incense, candle, and $\mathrm{T}_{\mathrm{i}} \mathrm{O}_{2}$ have been measured [12-15].

Even though many studies have been conducted on the combustion characteristics and emissions of WCO biodiesel, limited literature has reported the LDSA concentration of solid particles from WCO biodiesel. In this study, the characteristics of solid particles emitted from WCO biodiesel in an agricultural single-cylinder direct-injection compression-ignition engine were investigated. The engine operating conditions were 1200, 1400, 1600 and 1800 rpm engine speed, and 10 to $95 \mathrm{Nm}$ engine load. A portable emission measurement system (NanoMet3) was used to measure exhaust solid particles. An evaporative tube with a temperature of $575 \mathrm{~K}$ was used to remove volatile hydrocarbons from the exhaust, allowing the measurement of solid particles by the NanoMet3 emission measurement system. In this study, in addition to LDSA concentration, other parameters such as solid particle number concentration, mass concentration, and mean diameter are also reported. The same tests were conducted for conventional fossil-based diesel, and the results were used as benchmark to those of WCO biodiesel.

\section{Experimental system and methods}

\subsection{Engine and Instrumentation.}

The experiments in this study were performed in a single-cylinder direct-injection compression-ignition engine with a bore of $135 \mathrm{~mm}$, a stroke of $125 \mathrm{~mm}$, a displacement of $1.789 \mathrm{~L}$, and a compression ratio of 16.5:1. The basic schematic diagram of the experimental setup is shown in. The specifications of the engine are summarized in Table 1.

The Engine is coupled with an eddy current dynamometer (model number: DW160) produced by the Sichuang Chengbang Science and Technology Company, China. Its rated torque is $600 \mathrm{Nm}$ at $2800 \mathrm{rpm}$. Its maximum absorbing power is $160 \mathrm{~kW}$, and its maximum speed is $6500 \mathrm{rpm}$. The engine speed can be controlled by the eddy current dynamometer with an accuracy of $\pm 1 \mathrm{rpm}$, regardless of the engine power output. Air is introduced into the cylinder through the air filter and intake runner. The engine has a direct-injection system and an evaporative cooling system. Exhaust gas temperature were measured with K-type thermocouple.

The exhaust sample was taken from the exhaust runner, $0.23 \mathrm{~m}$ downstream of the exhaust ports. NanoMet3, a portable emission measurement systems supplied by Testo (Germany), was used to measure parameters such as particle number concentration, average size, and LDSA. Particle mass concentration was also calculated based on the particle number concentration and their average size. An evaporation tube with the maximum operating temperature of $573 \mathrm{~K}$ was used to remove all volatile components in the exhaust sample. The sensor calibration of the NanoMet3 instrument was performed with standard $\mathrm{NaCl}$ particles.

The fuel consumption was measured by a fuel flow meter (model number: ET2500) produced by the Sichuang Chengbang Science and Technology Company (China). The fuel consumption measurement range was $0-500 \mathrm{~g}$, with an the accuracy of $\pm 0.4 \% \mathrm{FS}$. 


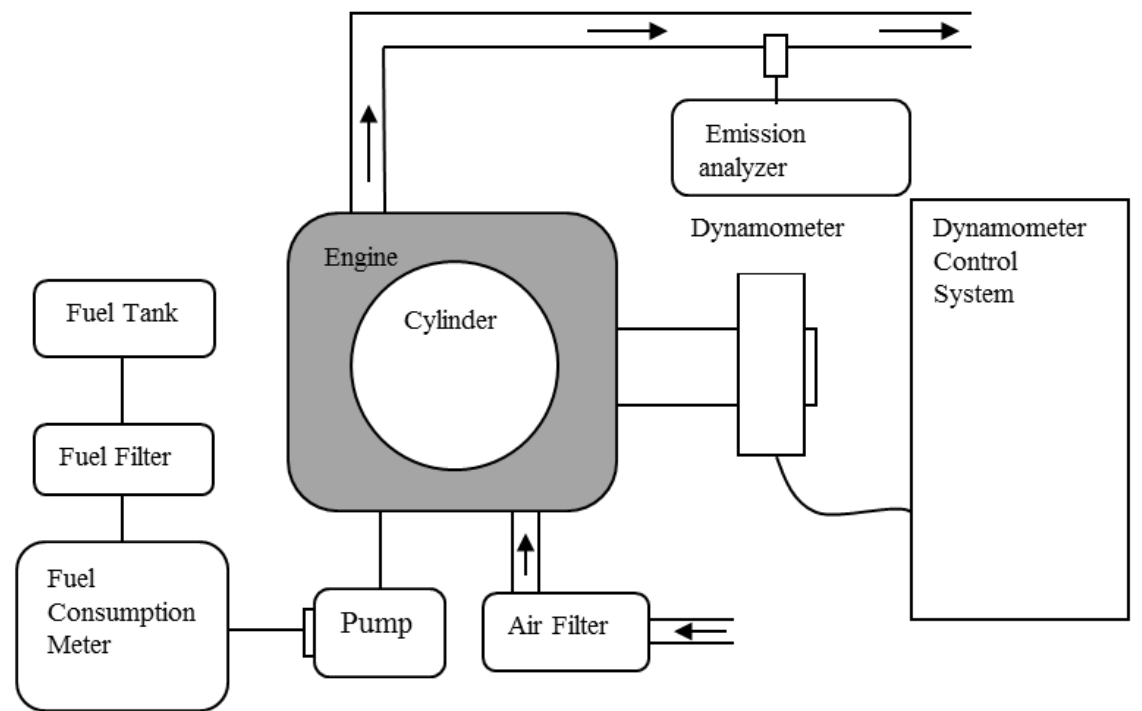

Fig. 1 Schematic diagram of experimental setup

Table 1 Specifications of engine

\begin{tabular}{cc}
\hline Item & Specification \\
\hline Number of cylinders & 1 \\
Injection system & Direct-injection \\
Valves per cylinder & 2 \\
Cycle & 4 stroke \\
Maximum torque $(\mathrm{Nm})$ & $121.5 @ 1760 \mathrm{rpm}$ \\
Rated power $(\mathrm{kW})$ & $25 @ 2200 \mathrm{rpm}$ \\
Bore $(\mathrm{mm})$ & 135 \\
Stroke $(\mathrm{mm})$ & 125 \\
Displacement $\left(\mathrm{cm}^{3}\right)$ & 1789 \\
Type of cooling & Evaporative cooling \\
Compression ratio & 16.5 \\
\hline
\end{tabular}

\subsection{Test Fuels.}

The fossil-based diesel was purchased from a service station in Hubei province in China. The WCO biodiesel was purchased in Hubei province in China. Table 2 lists the main fuel properties. The cetane numbers of the fossil-based diesel and WCO biodiesel are 45 and 50, respectively. The lower heating values of fossil-based diesel and WCO biodiesel are $42.4 \mathrm{MJ} / \mathrm{kg}$ and $39.5 \mathrm{MJ} / \mathrm{kg}$, respectively. The low energy density of WCO biodiesel is mainly due to its oxygen content. The densities of fossil-based diesel and WCO biodiesel are $830 \mathrm{~kg} / \mathrm{m}^{3}$ and $880 \mathrm{~kg} / \mathrm{m}^{3}$ at the temperature of $293 \mathrm{~K}$, respectively. The kinematic viscosities of fossil-based diesel and WCO biodiesel are $3.4 \mathrm{~mm}^{2} / \mathrm{s}$ and $4.6 \mathrm{~mm}^{2} / \mathrm{s}$ at the temperature of $313 \mathrm{~K}$, respectively. The flash points of fossil-based diesel and WCO biodiesel are 329K and 433K, respectively.

\subsection{Test Procedure.}

The engine was started and warmed up until the pre-set oil temperature was reached by using either traditional fossil-based diesel or WCO biodiesel combustion. After the warm-up phase, the engine tests were conducted at the engine speeds of 1200, 1400, 1600 and $1800 \mathrm{rpm}$, and at engine loads ranging from 10 to $95 \mathrm{Nm}$. For each test point, the engine was stabilized for 10 minutes before measurements were taken. In order to reduce the measurement error, each test point was repeated at least three times. After finishing the test for the first fuel, the fuel in the tank was drained, and the second fuel was added to the tank. The engine was run for at least 30 minutes, in order to consume the remainders of the first fuel in the fuel system. Then the experiment was repeated under the same procedure for the second fuel. The tests were conducted for several days by alternating the order of fuels. 


\section{Results and Discussion}

In this section, the particle emission results at the different engine speeds and loads for diesel and WCO biodiesel are presented. The parameters discussed here include the Particle number and LDSA concentration, particle mean diameter, and particle mass concentration. In addition, response surface methodology (RSM) is used to model the particle LDSA concentration.

\subsection{Particle Number and LDSA Concentration.}

Fig. 2 shows the particle number concentrations observed under the different operating conditions. The particulate number concentrations at the different speeds and loads were measured for diesel and WCO biodiesel. At low load (torque $<40 \mathrm{Nm}$ ), the particle number concentrations of the engine fueled with diesel are similar to those of WCO biodiesel. This is because less fuel was injected into the combustion chamber at low load; whilst the cylinder intake air through the intake runner was almost the same due to the nature of how diesel engines operate. Thus, more oxygen was available for combustion at low load than at high load. The rich oxygen environment discouraged soot formation and encouraged soot oxidation. The viscosity of WCO biodiesel is larger than that of traditional diesel, which causes poorer atomization of WCO biodiesel as compared to diesel. The synergic effects of oxygen content in the fuel, rich oxygen atmosphere in the combustion chamber, and the viscosity of fuels lead to the similar particle number concentration of diesel and WCO biodiesel at low loads. At high load (torque $>60 \mathrm{Nm}$ ), the particle number concentrations of the engine fueled with diesel were more than those of WCO biodiesel. This was due to the oxygen content in the WCO biodiesel, which improved the in-cylinder combustion for the WCO biodiesel. There was no oxygen content in the diesel; it depends on the oxygen from the intake air for combustion. The air-fuel ratio in the combustion chamber at high load conditions was lower than that at low load. Consequently, the diesel that was sprayed into the combustion chamber could not be oxygenated as completely as WCO biodiesel.

Fig. 3 shows the LDSA concentration under the different operating conditions for diesel and WCO biodiesel at the different speeds and loads. Compared to diesel, the WCO biodiesel lead to similar LDSA concentrations at low loads, and higher LDSA concentrations at high loads. The overall trend in the results of Fig. 2 and Fig.3 is similar.
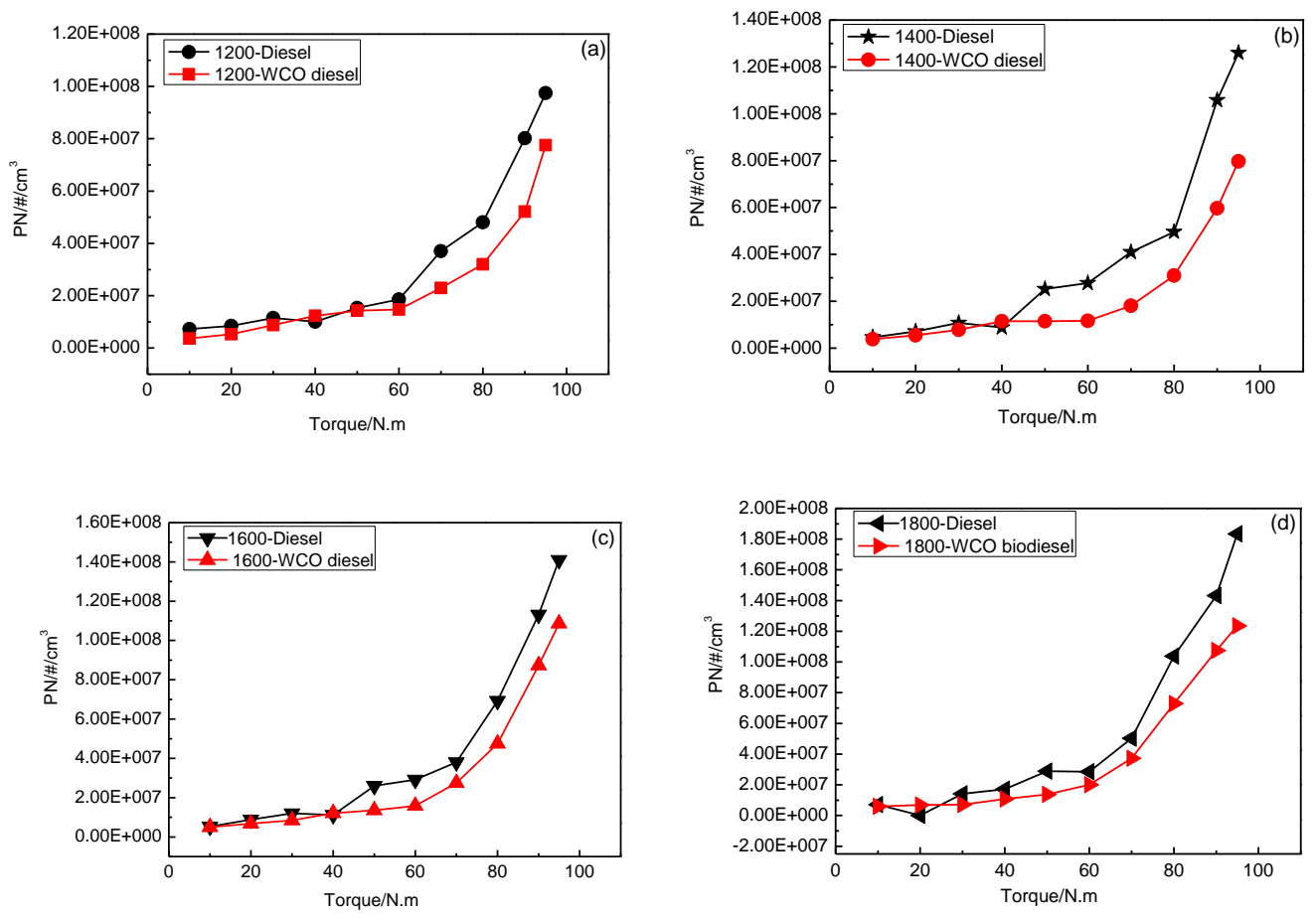

Fig. 2 Particle number concentration: (a) 1200r/min; (b) 1400r/min; (c) 1600r/min; (d) 1800r/min 

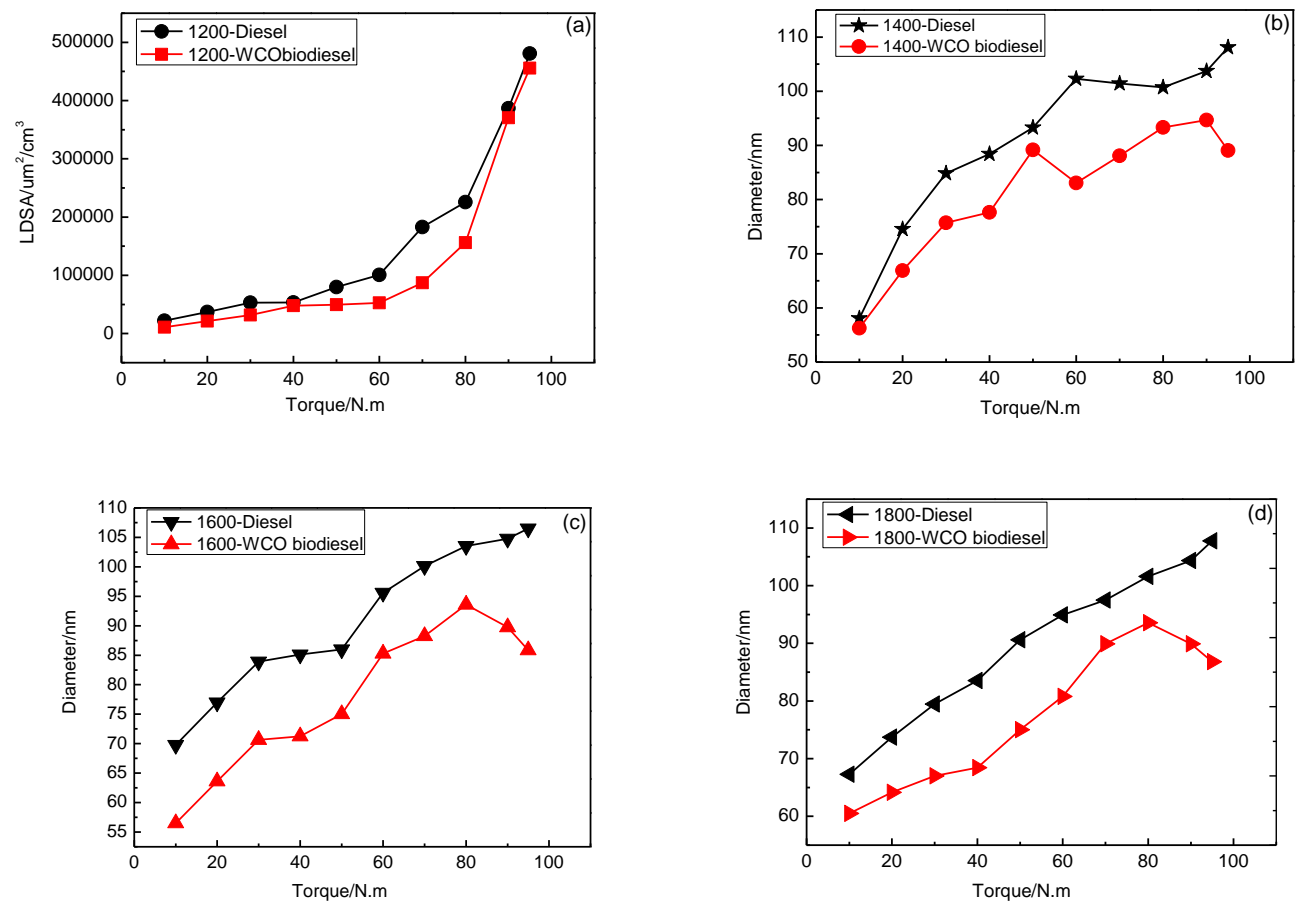

Fig. 3 LDSA concentration: (a) 1200r/min; (b) 1400r/min; (c) 1600r/min; (d) 1800r/min

\subsection{Particle Mean Diameter Analysis.}

Fig. 4 shows the particle mean diameter under the different operating conditions for diesel and WCO biodiesel at the different speeds and loads. It is clear that the particle mean diameter for diesel was larger than that of WCO biodiesel, regardless of engine load and speed. Unlike the particle number concentrations, the particle mean diameter differences between the two fuels was not that sensitive to the engine load. Therefore, it can be concluded that, at low load, WCO biodiesel produces similar numbers of particles as diesel, however, the particle sizes are smaller. At high load, WCO biodiesel produces less total particles and smaller particles than diesel.
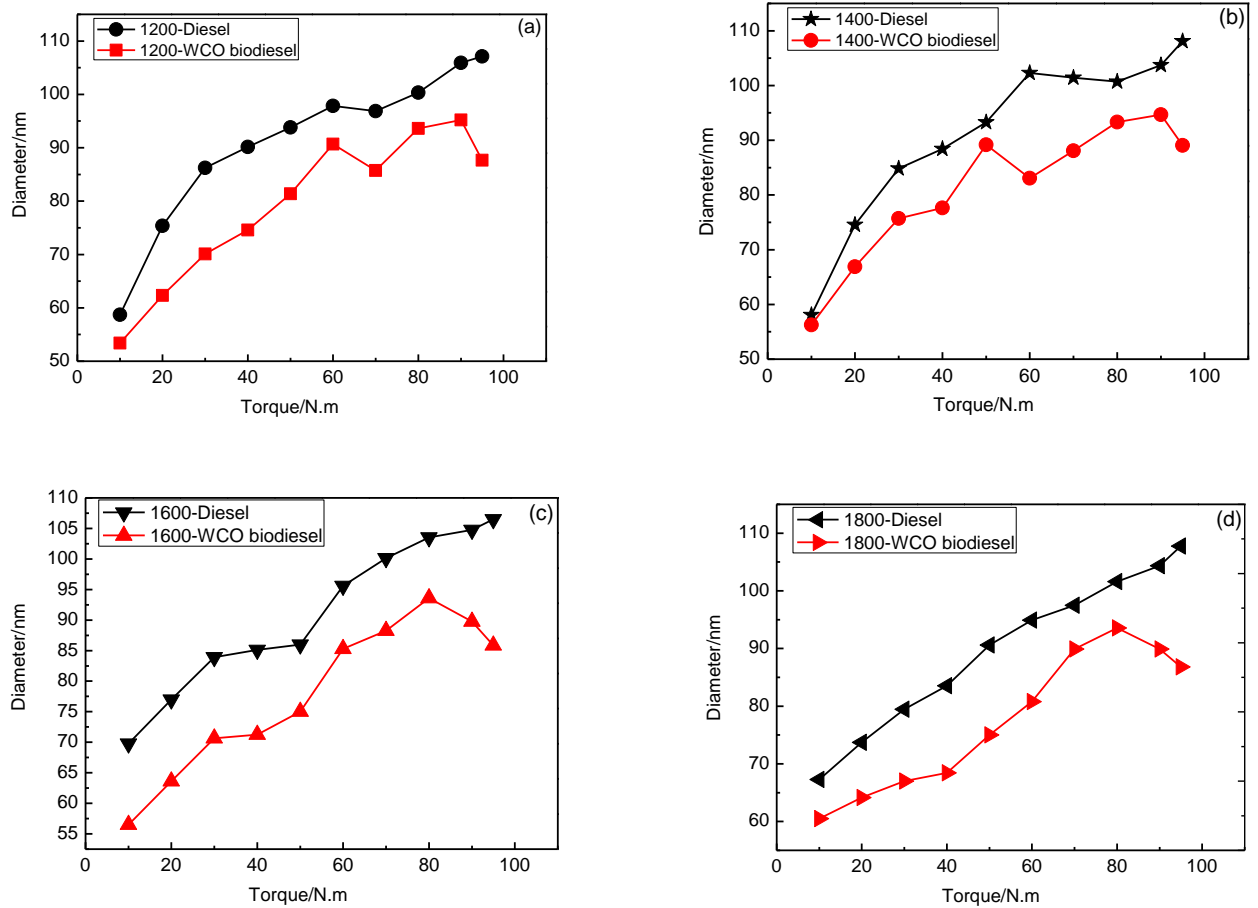

Fig. 4 Particle mean diameter: (a) 1200r/min; (b) 1400r/min; (c) 1600r/min; (d) 1800r/min 


\subsection{Particle Mass Concentration.}

Fig. 5 shows the particle mass concentration under the different operating conditions for diesel and WCO biodiesel at the different speeds and loads. It is clear that the particle mass concentration for the diesel was larger than that of WCO biodiesel, regardless of engine speed, however, more differences in the particle mass concentration were observed at higher load. This is mainly due to the oxygen content in the WCO biodiesel.
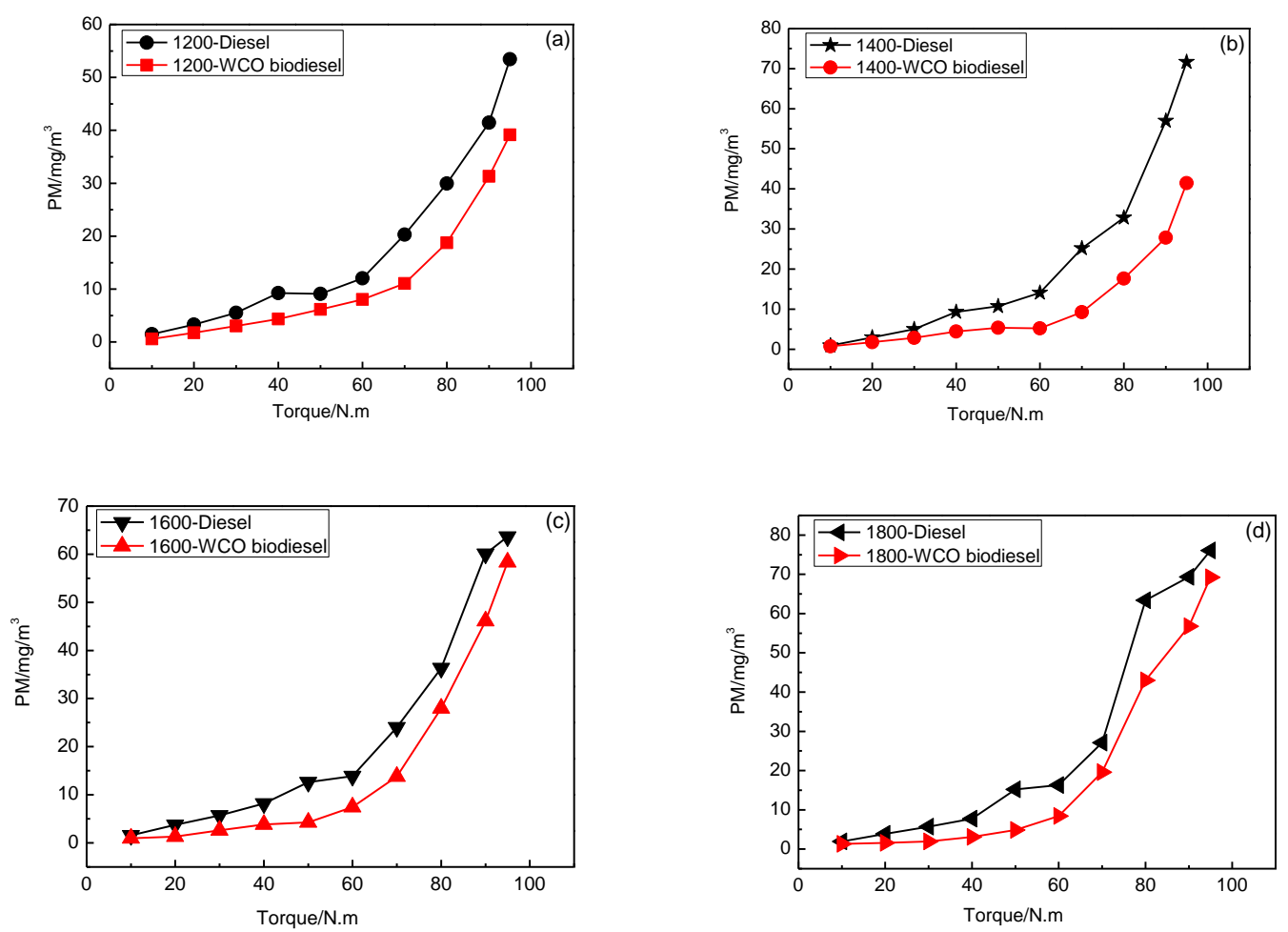

Fig. 5 Particle mass concentration: (a) 1200r/min; (b) 1400r/min; (c) 1600r/min; (d) 1800r/min
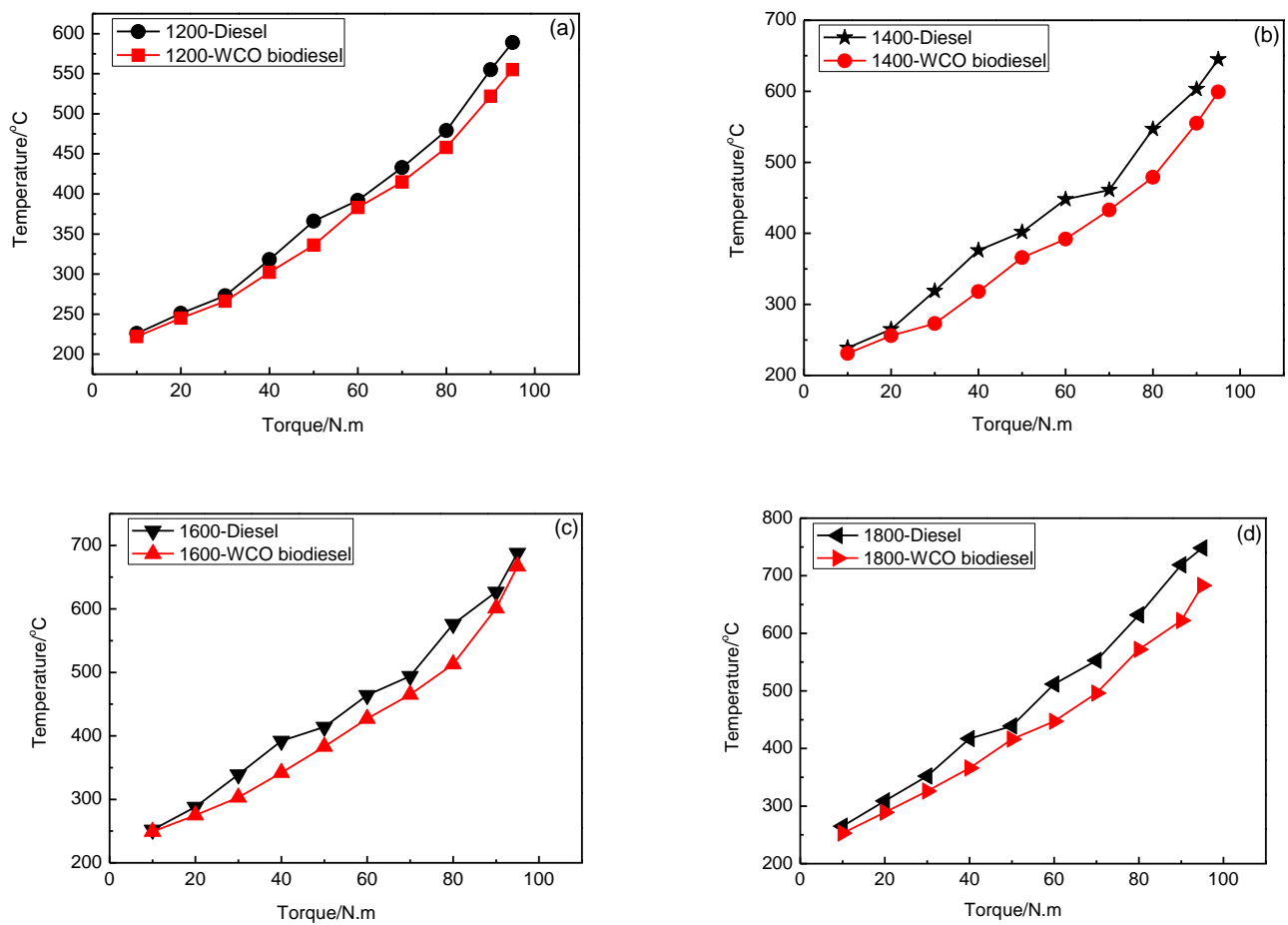

Fig. 6 Exhaust Gas Temperature: (a) 1200r/min; (b) 1400r/min; (c) 1600r/min; (d) 1800r/min 


\subsection{Exhaust Temperature.}

Fig. 6 shows the exhaust gas temperature under the different operating conditions for diesel and WCO biodiesel at the different engine speeds and loads. The exhaust gas temperature of WCO biodiesel was up to 50 degrees lower than that of diesel, indicating that more chemical energy from WCO was converted into effective work on the piston than with diesel. This is due to the cetane number difference between the two fuels. The cetane numbers of the fossil-based diesel and WCO biodiesel were similar; they were 45 and 50, respectively, indicating that the ignition delay of the fossil-based diesel was longer than that of the WCO biodiesel. Thus, the WCO diesel burned faster and earlier than that of diesel, leading to its lower exhaust temperature.

\section{Conclusion}

In this study, the characteristics of solid particles emitted from WCO biodiesel in an agricultural single-cylinder direct-injection compression-ignition engine were investigated. The engine operating conditions were 1200, 1400, 1600 and $1800 \mathrm{rpm}$ engine speed, and 10 to $95 \mathrm{Nm}$ engine load. A portable emission measurement system (NanoMet3) was used to measure exhaust solid particles. An evaporative tube with a temperature of $575 \mathrm{~K}$ was used to remove volatile hydrocarbons from the exhaust, allowing the measurement of solid particles using the NanoMet3 emission measurement system. The same tests were conducted for conventional fossil-based diesel, and the results were used as benchmark to those of WCO biodiesel. The following are the conclusions drawn from the results and discussion:

1) At low load (torque $<40 \mathrm{Nm}$ ), the particle number and LDSA concentrations of the engine fuelled with diesel are similar to those of WCO biodiesel, due to excessive air in the cylinder, however, at high load (torque $>60 \mathrm{Nm}$ ), the particle number concentrations of the engine fuelled with diesel are more than these of WCO biodiesel. This is due to the oxygen content in the WCO biodiesel.

2) At low load, WCO biodiesel produces similar particle numbers to diesel, however, the particle size is smaller. At high load, WCO biodiesel produces less total particles and smaller particles than diesel.

3) The particle mass concentration for the diesel fuel is larger than that of WCO biodiesel, regardless of engine speed; however, more differences in the particle mass concentration are observed at higher load. This is mainly due to the oxygen content in the WCO biodiesel.

4) The exhaust gas temperature of WCO biodiesel is up to 50 degrees lower than that of diesel, indicating that more chemical energy from WCO is converted into effective work on the piston than with diesel. This is due to the cetane number difference between the two fuels.

\section{Acknowledgments}

This work was supported by the Educational Commission of Hubei Province of China (No.D20152603).

\section{References}

[1] M.S. Graboski, R.L. Mccormick. Combustion of fat and vegetable oil derived fuels in diesel engines. Progress in Energy and Combustion Science. Vol. 24(1998), p.125-164.

[2] C.M. Wang, S. Zeraati-Rezaei, L.M. Xiang, et al. Ethanol blends in spark ignition engines: RON, octane-added value, cooling effect, compression ratio, and potential engine efficiency gain. Applied Energy Vol. 191(2017), p.603-619.

[3] C.M. Wang, H.M. Xu, J.M. Herreros, et al. Impact of Fuel and Injection System on PM Emissions from a DISI Engine. Applied Energy. Vol. 132(2014), p.178-191.

[4] C.M Wang, A. Janssen, Prakash A, et al. Splash blended ethanol in a spark ignition engine - Effect of RON, octane sensitivity and charge cooling. Fuel.Vol.196(2017), p.21-31.

[5] J. Hwang, D. Qi, Y. Jung, et al. Effect of injection parameters on the combustion and emission 
characteristics in a common-rail direct injection diesel engine fueled with waste cooking oil biodiesel. Renew Energy. Vol. 63(2014), p.9-17.

[6] C. S. Cheung, X. J. Man, K.W. Fong, et al. Effect of waste cooking oil biodiesel on the emissions of a diesel engine. Energy Procedia. Vol. 66(2015), p.93-96.

[7] J. Hwang, Y. Jung, C. Bae. Comprehensive assessment of soot particles from waste cooking oil biodiesel and diesel in a compression ignition engine.SAE International Journal of Fuels and Lubricants. Vol. 8(2015), p.290-297.

[8] T. Lu, C. Cheung, Z. Huang. Influence of waste cooking oil biodiesel on the particulate emissions and particle volatility of a DI diesel engine. Aerosol Air Qual Res. Vol. 13(2013), p.243-254.

[9] L. Wei, C. Cheung, Z. Ning. Influence of waste cooking oil biodiesel on the nanostructure and volatility of particles emitted by a direct-injection diesel engine. Aerosol Science and Technology. Vol.50(2016), p.893-905.

[10] L. Zhu, Y. Xiao, C.S. Cheung, et al. Combustion, gaseous and particulate emission of a diesel engine fueled with n-pentanol (C5 alcohol) blended with waste cooking oil biodiesel. Applied Thermal Engineering. Vol. 102(2016), p.73-79.

[11] R. Betha, R. Balasubramanian. Particulate emissions from a stationary engine fueled with ultra-low-sulfur diesel and waste-cooking-oil-derived biodiesel. Journal of the Air \& Waste Management Association. Vol.61(2011), p.1063-1069.

[12] O. Geiss, I.Bianchi, J.Barrero-Moreno. Lung-deposited surface area concentration measurements in selected occupational and non-occupational environments. Journal of Aerosol Science. 96(2016), p.24-37.

[13] C. Reche, M. Viana, M. Brines, et al. Determinants of aerosol lung-deposited surface area variation in an urban environment. Science of The Total Environment. Vol 517(2015), p.38-47.

[14] A. Leavey, J. Fang, M. Sahu, et al. Comparison of measured particle lung-deposited surface area concentrations by an Aerotrak 9000 using size distribution measurements for a range of combustion aerosols. Aerosol Science and Technology. 47(2013), p.966-978.

[15] H. Kuuluvainen, T. Rönkkö, A. Järvinen, et al. Lung deposited surface area size distributions of particulate matter in different urban areas. Atmos Environ. Vol.136(2016), p.105-113. 